\title{
Significance of audio-vestibular evaluation in diabetes mellitus patients- A study
}

\author{
Mohamed Ashraf Kuniyil ${ }^{1}$, Subhodha Hosagadde Rathnakara ${ }^{2 *}$, Prakruthi Jaladhar ${ }^{3}$, Nimalka M \\ Sequeira $^{4}$, Vijayalakshmi Subramaniam ${ }^{5}$
}

${ }^{1}$ Junior Resident, ${ }^{2}$ Senior Resident, ${ }^{3}$ Assistant Professor, ${ }^{4}$ Audiologist and Speech Language Pathologist, ${ }^{5}$ Professor and Head, Dept. of ORL, Yenepoya Medical College, Mangalore, Karnataka

*Corresponding Author: Subhodha Hosagadde Rathnakara

Email: subhodh.hr@gmail.com

\begin{abstract}
Introduction: Diabetes mellitus (DM) has a projected rise in its affected population to almost double by the year 2035 in India. Ongoing research regarding its microvascular complications has led to a disparity of opinion about involvement of the audio-vestibular system. Hence to evaluate the audio-vestibular functions in patients with diabetes mellitus and determine their correlation with duration and control of the disease, this study was conducted.

Materials \& Methods: 97 DM patients were included in this prospective, cross-sectional study and all of them underwent clinical examination, Dix-Hallpike maneuver and investigations like Pure tone audiometry (PTA) and Videonystagmography (VNG).

Results: 64 of 97 patients, had varying degrees of sensorineural hearing loss on PTA and 16 patients had vestibular hypofunction noted on caloric test of VNG. It was identified that the occurrence of bilateral hearing loss and vestibular hypofunctioning were statistically significant with chi square test ( $\mathrm{p}$ value 0.028 and $<0.001$ respectively), when 5years duration of DM was taken for cut off. Analysis of symptoms with PTA and VNG, found significant correlation of tinnitus and hearing loss ( $\mathrm{p}$ value 0.03 and $<0.001$ respectively) with abnormal findings in both the investigations, revealing a subclinical nature of the vestibular dysfunction. However, there were no significant correlations found with the glycaemic control of DM.

Conclusions: It is advisable to consider audio-vestibular evaluation with PTA and VNG, as screening tests for long term DM patients with or without symptoms of giddiness and hearing loss as a step for early identification of microvascular complications of the inner ear, though larger studies in other populations needs to be done for further confirmation of the correlation.
\end{abstract}

Keywords: Diabetes mellitus, hearing loss, vestibular dysfunction, Pure tone audiometry (PTA), Videonystagmography (VNG).

\section{Introduction}

Diabetes mellitus (DM) is a chronic metabolic disease associated with high levels of blood glucose and it is considered a personal, social and economic burden for the patients, families, and institutions. India is considered the diabetes capital of the world. ${ }^{1}$ Yesudian et $\mathrm{al}^{2}$ outlined the economic burden of diabetes in India, which reviewed 19 studies from different parts of India and this study projected a sharp rise of DM affected people, from 65.1 million in 2013 to rise to 109 million by 2035 making it a national health concern.

As a result, there has been a vast amount of ongoing research devoted to DM and complications associated with the disease. People with diabetes often develop multiorgan anatomic and functional changes due to microvascular and macrovascular complications. ${ }^{3}$ Some of the recent studies show suspicion of alterations in audio-vestibular (AV) systems in patients with DM. ${ }^{4}$ It is proposed that the microvascular abnormalities in complicated diabetes mellitus are causing the auditory system failure and thereby hearing. However, due to discordance in literature the result remains unsettled. While few studies reported no correlation between DM and hearing loss, ${ }^{(5,6)}$ other studies found positive correlation. $^{7-9}$

An animal model study was conducted by Myers SF, Ross MD in $1987^{10}$ on Sprague-Dawley rats to identify the morphological evidence of vestibular pathology in long-term experimental diabetes mellitus II, found that there was an increased incidence of secondary lysosomes within the connective tissue cells as well as an accumulation of intracellular lipid droplets that increased with the level of hyperglycaemia. Many clinical studies have been conducted to know the relationship between diabetes and vestibular function, some were questionnaire based, ${ }^{11}$ others used VEMP ${ }^{12}$.

Diagnosis of audio-vestibular (AV) dysfunction in DM is based on detailed history including balance abnormalities and recent history of falls. ${ }^{13}$ The clinical 
examination along with videonystagmography (VNG) and pure tone audiometry (PTA) are essential to confirm the condition. VNG is the best tool to evaluate vestibular dysfunction ${ }^{14}$. The present study was planned with the above background with an objective to assess the presence of AV dysfunction in DM patients and the need to screen them for same.

\section{Materials and Methods}

The study was an observational, prospective, cross sectional study at a tertiary care center in the western coast of South India with 97 patients in the study group. It included all adult patients presenting with diabetes mellitus to Dept. of ENT, both in-patients and out-patients. Patients with middle ear/external ear disease, head injury or trauma to ear, patients on or having history of consumption of ototoxic drugs and patients with cervical radiculopathy were excluded. The objectives of the study were explained to the participants, following which written informed consent was taken. Institutional ethics committee approval was obtained prior to commencement of the study. Detailed history of these patients regarding the duration of the disease, medications were noted and history of any recent falls or balance disorders or other systemic diseases along with detailed clinical otolaryngology examination which include ear, nose, throat examination and Dix Hallpike maneuver was done. Patients' blood glucose status was established by checking their glycosylated Hemoglobin levels and fasting and post prandial blood glucose levels. All the patients were subjected to Videonystagmography (VNG) and Pure tone audiometry (PTA)

\section{Pure tone audiometer}

Pure tone audiometry was done, using a calibrated Inter-acoustics Clinical audiometer-AC-40 (Denmark). TDH 39 Supra Aural Headphone was used with the transducer - Radio Ear B 71 bone vibrator. The threshold estimation was done using Modified Hughson-Westlake procedure (ASHA 1978). It was in accordance to the American National Standard Institute (ANSI) and was taken for all the frequency octaves from $250 \mathrm{~Hz}$ to $8000 \mathrm{~Hz}$.

Severity of the hearing loss was quantitatively calculated based on the Clark's (1981) modification of Goodman classification of severity of hearing loss (1965). Categories of Degrees of Hearing Loss, based on Air Conduction Pure-Tone Average at 500, 1000, and $2000 \mathrm{~Hz}$.

\begin{tabular}{|l|l|}
\hline Degree of hearing loss & Pure-Tone Average Range \\
\hline Normal hearing sensitivity & $-10 \mathrm{~dB}$ HL to 15 dB HL \\
\hline Slight hearing loss & $16 \mathrm{~dB}$ HL to 25 dB HL \\
\hline Mild hearing loss & $26 \mathrm{~dB}$ HL to 40 dB HL \\
\hline Moderate hearing loss & $41 \mathrm{~dB}$ HL to 55 dB HL \\
\hline Moderately severe hearing loss & $56 \mathrm{~dB}$ HL to 70 dB HL \\
\hline Severe hearing loss & $71 \mathrm{~dB}$ HL to 90 dB HL \\
\hline Profound hearing loss & $\begin{array}{l}91 \mathrm{~dB} \text { HL to equipment } \\
\text { limits }\end{array}$ \\
\hline
\end{tabular}

\section{Videonystagmography}

Videonystagmography was performed using BIOMED eVNGUSB (software version 1.1.5.2, Germany), with the help of camera attached to the infrared goggles worn by the patient.

\section{Tests included}

1. Calorie test (Temperature from 20-degree Celsius to 47-degree Celsius)

2. Smooth pursuit test

3. Saccade Test

4. Optokinetic nystagmus

\section{Results}

The data were tested for its distribution using the Shapiro-Wilk test of normality using Statistical Package for Social Sciences (version 22.0). The results showed that the data were not normally distributed. Hence, non-parametric tests were used for within- and between-group comparisons. Chi square test was used to check the association between the parameters. $\mathrm{p}<0.05$ was considered significant. Table 1 summarizes the demographic characteristics of participants.

Table 1: Demographic characteristics of participants:

\begin{tabular}{|c|c|}
\hline Patient parameters & Value (\%) \\
\hline Age - Mean (in years) & $54.68( \pm 10.68)$ \\
\hline Male & $54(55.67 \%)$ \\
\hline Female & $43(44.33 \%)$ \\
\hline Diabetes Mellitus & \\
\hline Duration: & $77(79.38 \%)$ \\
$<5$ years & $20(20.62 \%)$ \\
$>5$ years & \\
Diabetes Control: & $46(47.42 \%)$ \\
HbA1C $<7$ & $51(52.58 \%)$ \\
HbA1C $>7$ &
\end{tabular}


Table 2: Comparison of symptoms, PTA, VNG results with diabetes duration:

\begin{tabular}{|c|c|c|c|c|c|}
\hline \multirow{2}{*}{ Symptoms } & \multicolumn{4}{|c|}{ Duration of DM } & \multirow{2}{*}{ p value } \\
\hline & $\leq 5$ years & $\%$ & $>5$ years & $\%$ & \\
\hline HEARING LOSS & 19 & 55.88 & 15 & 44.11 & \\
\hline TINNITUS & 24 & 68.57 & 11 & 31.43 & \\
\hline GIDDINESS & 38 & 77.55 & 11 & 22.45 & \\
\hline \multicolumn{6}{|l|}{ PTA } \\
\hline $\mathrm{U} / \mathrm{L}$ & 7 & 100 & 0 & 0 & 0.687 \\
\hline $\mathrm{B} / \mathrm{L}$ & 39 & 68.42 & 18 & 31.58 & $0.028 *$ \\
\hline NORMAL & 31 & 93.94 & 2 & 6.06 & \\
\hline VNG (caloric- normal) & 71 & 88.89 & 10 & 11.11 & \multirow[b]{2}{*}{$<0.001 *$} \\
\hline VNG (caloric- hypo) & 6 & 37.5 & 10 & 62.5 & \\
\hline
\end{tabular}

*signifies statistically significant values

On analysing the data, when duration of diabetes mellitus of 5 years was used as a cut off, it was identified that the occurrence of bilateral hearing loss and hypo functioning noted on caloric test of VNG were statistically significant with chi square test ( $\mathrm{p}$ value 0.028 and $<0.001$ respectively). On assessing individually as well, there was a significant correlation with duration of diabetes and caloric test performed on right and left ear respectively ( $\mathrm{p}$ value $<0.001$ for both ears). The above details are tabulated in table 2 . However, there was no association noted with gaze, saccades and optokinetic nystagmus.

There was no correlation with control of diabetes and hearing loss (bilateral/unilateral). Also, there was no correlation with control of diabetes and videonystagmography- caloric test, gaze, saccades and optokinetic nystagmus.

Table 3: Correlation of symptoms with investigations:

\begin{tabular}{|c|c|c|c|c|c|}
\hline \multirow{2}{*}{$\begin{array}{c}\text { Symptoms (no. of } \\
\text { patients) }\end{array}$} & \multicolumn{4}{|c|}{ Investigation } & p value \\
\cline { 2 - 6 } & $\begin{array}{c}\text { PTA } \\
\text { U/L }\end{array}$ & $\begin{array}{c}\text { PTA } \\
\text { B/L }\end{array}$ & $\begin{array}{c}\text { VNG (Caloric- } \\
\text { U/L) }\end{array}$ & $\begin{array}{c}\text { VNG (Caloric- } \\
\text { B/L) }\end{array}$ & \\
\hline HEARING LOSS (34) & 0 & 32 & 1 & 13 & $<0.001^{*}$ \\
\hline TINNITUS (35) & 2 & 27 & 0 & 11 & $0.03^{*}$ \\
\hline GIDDINESS (49) & 4 & 30 & 1 & 12 & 0.433 \\
\hline
\end{tabular}

*signifies statistically significant values

Table 3 describes the correlation of symptoms with results of PTA and VNG. It shows that the patients who presented with hearing loss and tinnitus had objective hearing loss measured by pure tone audiometry ( $\mathrm{p}$ value $<0.001$ ) than those who presented with giddiness. It was also identified that VNG showed hypofunction in patients who presented with hearing loss or tinnitus without complaints of giddiness ( $\mathrm{p}$ value $<0.001)$.

\section{Discussion}

Several studies have proposed that DM may exacerbate hearing loss and vestibular dysfunction and extensive investigations have been conducted in order to identify the pathophysiology. The proposed mechanisms in AV dysfunctions found in DM are probably an effect of angiopathy, neuropathy or both, as of the anatomic studies in animals conducted by Myers et al (1985 \& 1998) and Costa OA (1967). ${ }^{15-17}$
Microangiopathy of the vascular striae seems to be the major cause as supported by all related studies, mentioned earlier.

The results of the present study of 97 patients reveals mean age of 54.68+/-10.687 (from 30-77 years) among whom 54 were males. 64 of the 97(66\%) DM patients examined had some degree of SNHL, which is consistent with other studies. ${ }^{5,9,18-20}$ Tay et al ${ }^{18}$ in 1994 reported a higher incidence of hearing loss among DM patients as compared to non-diabetics with a significance of $\mathrm{P}<0.001$. In a meta-analysis, Akinpelu et al (2014) reported a significant incidence (44-69.7\%) in type 2 DM patients. ${ }^{20}$ Karkarlapudi et al, in $2003^{21}$ reported a $13.3 \%$ of hearing loss in diabetes mellitus patients than the subjects without DM. Among the patients with hearing loss in the present study, $89 \%$ had bilateral SNHL indicating that the hearing complications implicated in DM have a bilateral distribution. This result is consistent with 
similar studies; however, the proportion of the population with bilateral SNHL was highest in our study in comparison to others. ${ }^{9,19,21}$

The possible factors that influence the worsening of hearing thresholds in diabetics were evaluated. Presbycusis was ruled out by the nature of the audiological curves in PTA, which were mostly involving both the lower and higher frequencies in our patients, whereas in presbycusis, higher frequencies are commonly affected earlier in the process of hearing loss. ${ }^{22}$ In correlation studies, we found that the duration of the DM and hearing loss was found to be statistically significant $(p<0.001)$ when 5 year duration was considered as cut off. Some studies support this, by stating that the hearing threshold increases with increase in duration of diabetes, ${ }^{23,24}$ while others state no relation between hearing threshold and the duration. ${ }^{19,25,26}$

There was no correlation between the glycemic control and hearing loss. This was in consistency with studies by Cullen $\mathrm{R}$ et $\mathrm{al}^{26}$ and Deviprasad et $\mathrm{al}^{27}$ Although it was found to be significant in Type $1 \mathrm{DM}$ patients in a study by Okhovat SA et $\mathrm{al}^{28}$ and Panchu $\mathrm{P} .{ }^{19} \mathrm{We}$ also observed no gender differences regarding hearing loss. This finding was consistent with other studies, where no gender differences were observed amongst participants ${ }^{9}$, but there are reports of male diabetics having a greater deterioration of hearing as compared to females. ${ }^{26}$

However, relatively few studies have focused on the effects of DM on the vestibular functions. There are clinical studies demonstrating balance disorders in patients with $\mathrm{DM}^{11,29}$, which have a positive correlation of vestibular dysfunction with duration and control of DM. In Insulin-dependent-diabetes mellitus patients, Alessandrini et al ${ }^{30}$ noted significantly longer saccadic eye movement latency. Nicholson et $\mathrm{al}^{31}$ observed that both IDDM and NIDDM patients had abnormal gaze-holding, vestibulo-ocular reflex (VOR) and optokinetic nystagmus. Whereas, Di Nardo et $\mathrm{al}^{32}$ found normal findings in electronystagmography (ENG) in DM (Insulin dependent) patients with and without peripheral neuropathy. Klagenberg et $\mathrm{al}^{33}$ reported that vestibular assessment was within normal limits in patients with IDDM. Results of the present study have demonstrated that statistically significant alterations were present in VNG in DM patients when considering the caloric test whereas the gaze, saccade, and optokinetic nystagmus were normal.

Another surprise correlation, in the present study was that of the symptoms and the PTA-VNG findings. Even though giddiness was the most common symptom followed by tinnitus and hearing loss, the latter complaints had a statistically significant correlation with positive VNG and PTA findings. This may be attributed to the subclinical vestibular dysfunction in patients who have symptoms of tinnitus and hearing loss. Among 49 patients with giddiness, only $26.53 \%$ had positive VNG finding which is like the study by Fonseca AS et $\mathrm{al}^{29}$ which had $40 \%$. Similar disparity was observed by Klagenberg et $\mathrm{al}^{33}$ where only $16.6 \%$ of total patients had giddiness and $60 \%$ of them were positive for VNG.

\section{Conclusion}

The statistically significant correlation between hearing loss and vestibular dysfunction in chronic DM patients of more than 5years duration which is attributed to the microvascular complications of angiopathy in the inner ear makes it worthy to consider audio-vestibular evaluation as a screening tool along with other screening tests regularly used in practice. The subclinical nature of vestibular dysfunction in these patients is notable as it may lead to significantly increased risk of fall. With a projected sharp rise of the DM affected population in the Indian subcontinent, it becomes more important to take remarkable steps to prevent the complications by implementing a regular audio-vestibular evaluation in these patients. However, large scale studies in various populations needs to be conducted to overcome the confusions that exists regarding the correlation.

\section{Conflicts of interest}

There are no conflicts of interest.

\section{Financial support and sponsorships} None.

\section{Ethical approval}

"All procedures performed in studies involving human participants were in accordance with the ethical standards of the institutional ethics committee (YEC 241/2018) and with the 1964 Helsinki declaration and its later amendments or comparable ethical standards."

\section{Informed consent}

"Informed consent was obtained from all individual participants included in the study."

\section{References}

1. Joshi SR, Parikh RM. India diabetes capital of the world: now heading towards hypertension. $J$ Assoc Physicians India 2007:55:323-4.

2. Yesudian, Charles A K. "The economic burden of diabetes in India: a review of the literature." Globalization and 
health vol. 10 80. 2 Dec. 2014, doi:10.1186/s12992-0140080-x

3. Cade WT. Diabetes-related microvascular and macrovascular diseases in the physical therapy setting. Phys Ther 2008;88: 1322 -35

4. Agrawal Y, Carey JP, Della Santina CC, Disorders of balance and vestibular function in US adults: data from the National Health and Nutrition Examination Survey, 20012004 [erratum in: Arch Intern Med. 2009;169:1419]. Arch Intern Med 2009;169:938-44.

5. Alvarenga KF, Duarte JL, Silva DPC, Agostinho-Pesse RS, Negrato CA, Costa OA et al. P300 cognitive potential on subjects with diabetes mellitus. Braz J Otorhinolaryngol 2005;71(2):202-7.

6. Maia CAS, Campos CAH. Diabetes mellitus as etiological factor of hearing loss. Braz J Otorhinolaryngol 2005;71(2):208-14,

7. Pemmaiah KD, Srinivas DR. Hearing loss in diabetes mellitus. Int J Collab Res Intern Med Public Health 2011;3(10):725-731

8. Tay HL, Ray N, Ohri R, Frootko NJ. Diabetes mellitus and hearing loss. Clin Otolaryngol 1995;20:130-134

9. Malucelli DA, Malucelli FJ, Fonseca VR, Zeigeboim B, Ribas A, da Trotta F et al. Hearing loss prevalence in patients with diabetes mellitus type 1 . Braz $J$ Otorhinolaryngol 2012;78(3):105-115

10. Myers SF, Ross MD. Morphological evidence of vestibular pathology in long-term experimental diabetes mellitus II, connective tissue and neuroepithelial pathology. Acta Otolaryngol 1987;104:40-9.

11. Agrawal Y, Carey JP, Della Santina CC, Schubert MC, Minor LB. Diabetes, vestibular dysfunction, and falls: analyses from the National Health and Nutrition Examination Survey. Otol Neurotol 2010; 31: 1445-50

12. Bektas D, Gazioglu S, Arslan S, Cobanoglu B, Boz C and Caylan $\mathrm{R}$ et al. VEMP responses are not affected in noninsulin-dependent diabetes mellitus patients with or without polyneuropathy. Acta oto-laryngologica, 2008:128(7):76871.

13. D'Silva, Linda J. "Impact of Diabetic Complications on Balance and Falls: Contribution of the Vestibular System." Physical Therapy 2016;96(3): 400-9. PMC. Web. 13 Aug. 2018)

14. Mekki S. The role of videonystagmography (VNG) in assessment of dizzy patient. Egypt J Otolaryngol 2014;30(2):69

15. Myers SF. Myelin-sheath abnormalities in the vestibular nerves of chronically diabetic rats. Otolaryngol Head Neck Surg 1998;119:432-8.

16. Myers SF, Ross MD, Jokelainen P, Graham MD, McClatchey KD. Morphological evidence of vestibular pathology in long-term experimental diabetes mellitus. I. Microvascular changes. Acta Otolaryngol 1985;100:35164.

17. Costa OA. Inner ear pathology in experimental diabetes. Laryngoscope LXXVII, 1967: 68-75.

18. Tay HL, Ray N, Ohri R, Frootko NJ. Diabetes mellitus and hearing loss. Clin Otolaryngol1995; 20:130-4.
19. Panchu P. Auditory acuity in type 2 diabetes mellitus. Int $J$ Diabetes Dev Ctries 2008;28(4):114-120

20. Olubunmi V. Akinpelu, MD, MSc; Mario Mujica-Mota, MD; Sam J. Daniel, MD, MSc, FRCSC. Is Type 2 Diabetes Mellitus Associated With Alterations in Hearing? A Systematic Review and Meta-Analysis. Laryngoscope, 2014;124:767-76.

21. Kakarlapudi V, Sawyer R, Staecker H. The effect of diabetes on sensorineural hearing loss. Otol Neurotol 2003;24(1):382-6.

22. Demeester K, Wieringen Av, Jan-jaap H, Topsakal V, Fransen E, Laer Lv et al. Audiometric shape and presbycusis. Int J Audiol 2009; 48: 222-32

23. Zelenka.J \& Kozak.P. Disorder in blood supply of the inner ear as early symptom of diabetic angiopathy; J.Laryngology; 1965;79;4;314-19.

24. Virteniemi J, Laakso M, Nuutinen J, Karjalainen S, Vartiainen E. "Hearing thresholds in Insulin dependent diabetes mellitus", J laryngol Otol 1994; 108: 837-41.

25. Kurien M., Thomas K, Bhanu T.S. "Hearing threshold in patients with diabetes mellitus", J Laryngol Otol 1989;103(2):164-8.

26. Cullen R, Cinnamond N.J. "Hearing loss in diabetes", $J$ laryngology Otol 1993;107:179-82.

27. Dosemane, Deviprasad \& Bahniwal, Rupinder \& Manisha, N. \& Khadilkar, Meera. (2018). Association Between Type 2 Diabetes Mellitus and Hearing Loss Among Patients in a Coastal City of South India. Indian J Otolaryngol Head \& Neck Surg 10.1007/s12070-018-1499-9.

28. Okhovat SA, Moaddab MH, Okhovat SH, Evaluation of hearing loss in juvenile insulin dependent patients with diabetes mellitus. J Res Med Sci 2011;16:179-83.

29. Fonseca AS, Davidsohn SA. Correlation between dizziness and impaired glucose metabolism. Braz J Otorhinolaryngol 2006;72:367-9.

30. Alessandrini M, Bruno E, Parisi V, Uccioli L, Giacomini PG. Saccadic eye movement and visual pathways function in diabetic patients. An Otorrinolaringol Ibero Am 2001; 28:269-80.

31. Nicholson M, King J, Smith PF, Darlington CL. Vestibuloocular, optokinetic and postural function in diabetes mellitus. Neuroreport 2002;13:153-7

32. Di Nardo W, Ghirlanda G, Cercone S, Pitocco D, Soponara C, Cosenza A, et al. The use of dynamic posturography to detect neurosensorial disorder in IDDM without clinical neuropathy. J Diabetes Complications 1999; 13:79-85.

33. Klagenberg KF, Zeigelboim BS, Jurkiewicz AL, MartinsBassetto J. Vestibulocochlear manifestations in patients with type I diabetes mellitus. Braz J Otorhinolaryngol 2007; 73:353-8.

How to cite: Kuniyil MA, Rathnakara SH, Jaladhar P, Sequeira NM, Subramaniam V. Significance of audiovestibular evaluation in diabetes mellitus patients- A study. IP J Otorhinolaryngol Allied Sci 2020;3(1):1822. 